\title{
Article \\ Optical Method and Biochemical Source for the Assessment of the Middle-Molecule Uremic Toxin $\beta 2$-Microglobulin in Spent Dialysate
}

\author{
Joosep Paats ${ }^{1, *}$, Annika Adoberg ${ }^{2}$, Jürgen Arund ${ }^{1}$, Ivo Fridolin ${ }^{1}\left(\mathbb{D}\right.$, Kai Lauri ${ }^{1,3}$, Liisi Leis ${ }^{2}$, Merike Luman ${ }^{1,2}$ \\ and Risto Tanner ${ }^{1}$
}

check for updates

Citation: Paats, J.; Adoberg, A.; Arund, J.; Fridolin, I.; Lauri, K.; Leis, L.; Luman, M.; Tanner, R. Optical Method and Biochemical Source for the Assessment of the Middle-Molecule Uremic Toxin B2-Microglobulin in Spent Dialysate. Toxins 2021, 13, 255. https://doi.org/ $10.3390 /$ toxins 13040255

Received: 12 February 2021

Accepted: 29 March 2021

Published: 31 March 2021

Publisher's Note: MDPI stays neutral with regard to jurisdictional claims in published maps and institutional affiliations.

Copyright: (C) 2021 by the authors. Licensee MDPI, Basel, Switzerland. This article is an open access article distributed under the terms and conditions of the Creative Commons Attribution (CC BY) license (https:/ / creativecommons.org/licenses/by/ $4.0 /)$.
1 Department of Health Technologies, Tallinn University of Technology, 19086 Tallinn, Estonia; Jurgen.Arund@taltech.ee (J.A.); Ivo.Fridolin@taltech.ee (I.F.); Kai.Lauri@synlab.ee (K.L.); Merike.Luman@regionaalhaigla.ee (M.L.); Risto.Tanner@taltech.ee (R.T.)

2 Centre of Nephrology, North Estonia Medical Centre, 13419 Tallinn, Estonia; Annika.Adoberg@regionaalhaigla.ee (A.A.); Liisi.Leis@regionaalhaigla.ee (L.L.)

3 SYNLAB Eesti OÜ, 10138 Tallinn, Estonia

* Correspondence: Joosep.Paats@taltech.ee

\begin{abstract}
Optical monitoring of spent dialysate has been used to estimate the removal of watersoluble low molecular weight as well as protein-bound uremic toxins from the blood of end stage kidney disease (ESKD) patients. The aim of this work was to develop an optical method to estimate the removal of $\beta 2$-microglobulin $(\beta 2 \mathrm{M})$, a marker of middle molecule $(\mathrm{MM})$ uremic toxins, during hemodialysis (HD) treatment. Ultraviolet (UV) and fluorescence spectra of dialysate samples were recorded from 88 dialysis sessions of 22 ESKD patients, receiving four different settings of dialysis treatments. Stepwise regression was used to obtain the best model for the assessment of $\beta 2 \mathrm{M}$ concentration in the spent dialysate. The correlation coefficient 0.958 and an accuracy of $0.000 \pm 0.304 \mathrm{mg} / \mathrm{L}$ was achieved between laboratory and optically estimated $\beta 2 \mathrm{M}$ concentrations in spent dialysate for the entire cohort. Optically and laboratory estimated reduction ratio (RR) and total removed solute (TRS) of $\beta 2 \mathrm{M}$ were not statistically different $(p>0.35)$. Dialytic elimination of MM uremic toxin $\beta 2 \mathrm{M}$ can be followed optically during dialysis treatment of ESKD patients. The main contributors to the optical signal of the MM fraction in the spent dialysate were provisionally identified as tryptophan (Trp) in small peptides and proteins, and advanced glycation end-products.
\end{abstract}

Keywords: $\beta 2$-microglobulin; hemodialysis; dialysis adequacy; middle molecule uremic toxins; optical monitoring; ultraviolet absorbance; fluorescence

Key Contribution: Middle molecule (MM) uremic toxins have considerable contribution to the overall optical properties of spent dialysate, which allows to optically monitor removal of MM toxins like $\beta 2$-microglobulin. Future research should address identifying specific MM uremic toxins behind the optical properties of MM fraction.

\section{Introduction}

The largest number of the end stage kidney disease (ESKD) patients are treated using hemodialysis (HD), which has remained one of the most expensive and time-consuming methods among the treatments of chronic diseases. Therefore, the monitoring of HD quality, related to the removal efficiency of the uremic solutes in dialysis, is important to ensure adequacy and cost-efficiency of the HD procedure [1,2]. Optical monitoring of the spent dialysate on the outflow from the dialysis machine is a promising alternative to dialysis adequacy estimation based on blood sampling [3]. While ultraviolet (UV) absorbance monitoring of the spent dialysate [4-6] enables determining urea-based dialysis quality parameters $[7,8]$, the potential of optical dialysis monitoring is wider. Earlier 
research has shown the potential of optical monitoring of the spent dialysate to estimate the removal of low molecular weight uremic toxins [9-14], elimination of electrolytes, such as phosphate and calcium, [15,16], and possibly for nutrition assessment [17]. As a result, the UV monitoring of the removal of low molecule weight uremic solutes by HD treatment has become commonly applied in the treatment practice worldwide [18-20]. Furthermore, fluorescence of spent dialysate has proved to be well applicable for online removal monitoring of protein-bound uremic toxins [21-23]. However, many recent publications have confirmed the essential role of middle molecule (MM) group of uremic toxins in pathology and mortality of ESKD patients [24-28]. Despite promising works exploring the correlation between optical properties of spent dialysate and MM molecules, the biochemical origin of the MM toxins' optical contribution to the optical signal has not yet been revealed [29-31]. Still, the optimization of the removal of MM uremic solutes has remained an unsolved problem in the treatment of ESKD patients [32].

The aim of this study was to develop an improved optical method based on the UV absorbance and fluorescence of the spent dialysate for the assessment of the concentration of $\beta 2$-microglobulin ( $\beta 2 \mathrm{M})$ in the spent dialysate as the specific marker of MM uremic toxins in dialysate, and to explore the methods' biochemical origins.

\section{Results}

\subsection{Correlations between Optical Data and Concentration of $\beta 2 M$ in Dialysate}

Correlations between UV absorbance of spent dialysate at different wavelengths and concentration of $\beta 2 \mathrm{M}$ in spent dialysate can be seen in Figure 1 based on the data from all three hemodiafiltration (HDF) modalities (including the tank samples). The best correlation was observed at the UV wavelengths around $222 \mathrm{~nm}\left(\mathrm{R}^{2}=0.881\right)$. The range of UV absorption of aromatic amino acids at $275-280 \mathrm{~nm}$ exhibited a slightly weaker correlation $\left(R^{2}=0.862\right)$; surprisingly, quite a good correlation became evident at the wavelength of $311 \mathrm{~nm}\left(\mathrm{R}^{2}=0.865\right)$.

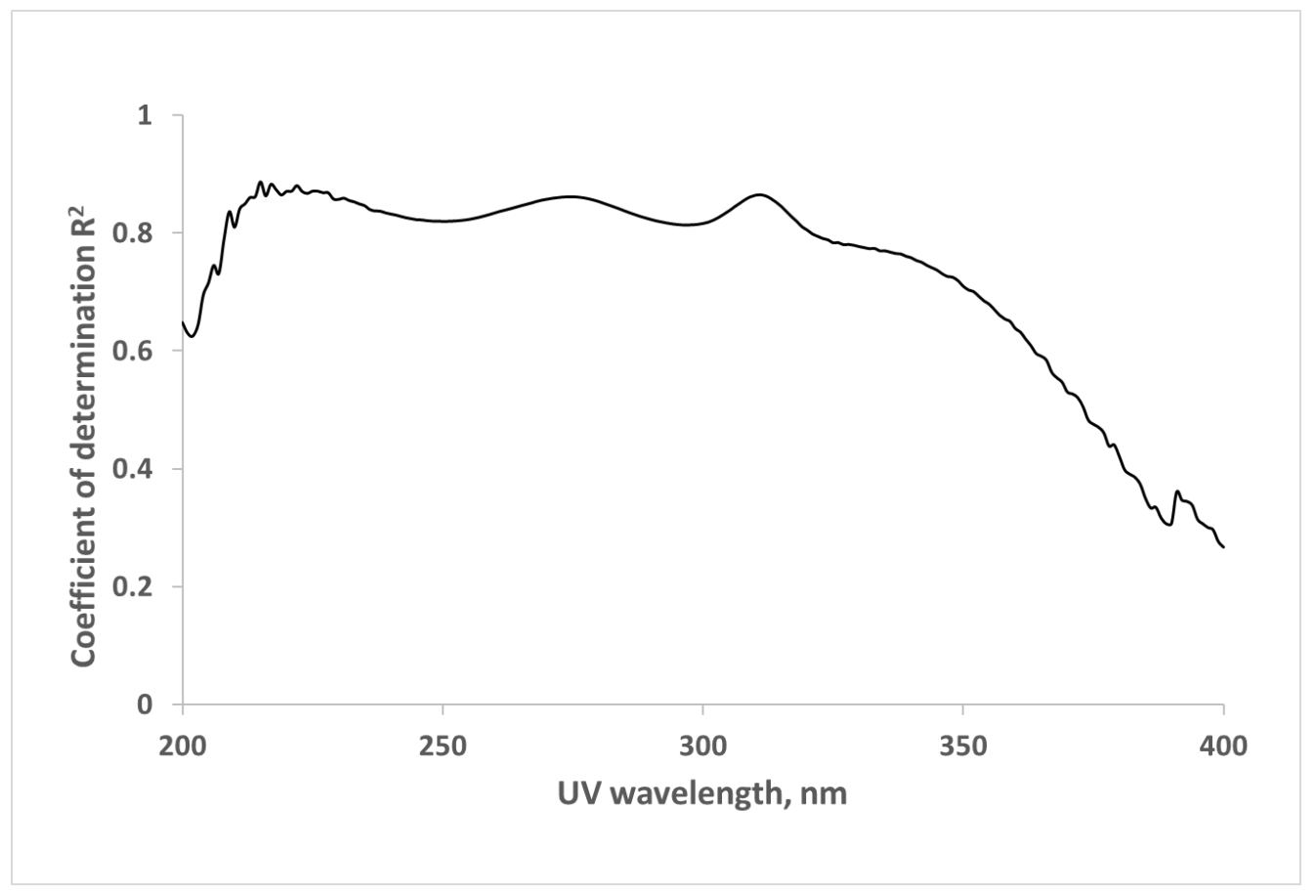

Figure 1. Wavelength dependence of the correlation between ultraviolet (UV)-absorbance of spent dialysate and concentration of $\beta 2$-microglobulin ( $\beta 2 \mathrm{M})$ in spent dialysate for hemodiafiltration (HDF) modalities $(\mathrm{N}=375)$. 
The best correlation between the fluorescence of spent dialysate and the concentration of $\beta 2 \mathrm{M}$ in spent dialysate was found in the wavelength region Ex350-370/Em500-555 nm with the coefficient of determination $R^{2}$ up to 0.859 (Figure 2).

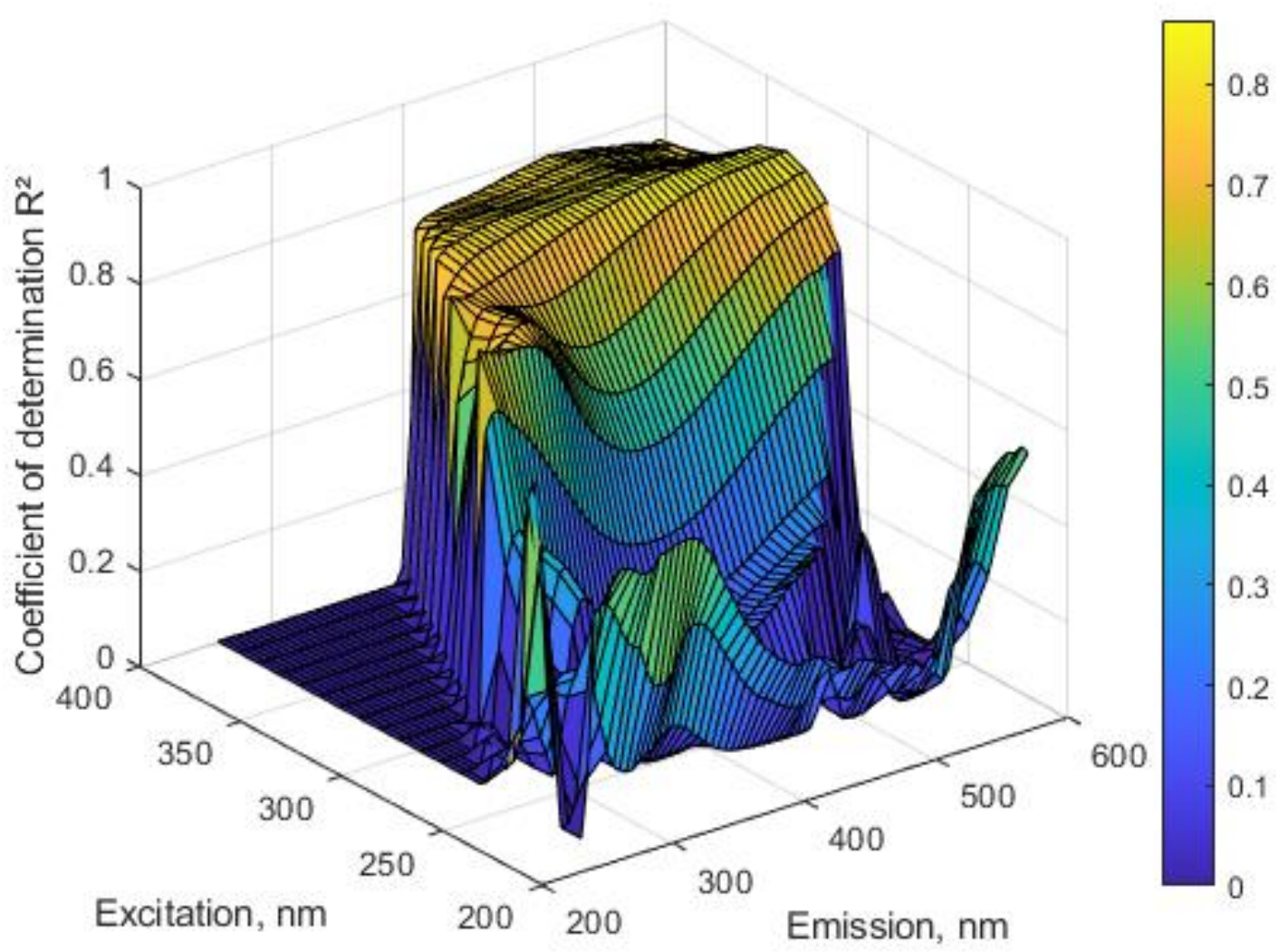

Figure 2. Wavelength dependence of the correlation between fluorescence intensity and concentration of $\beta 2 \mathrm{M}$ in spent dialysate for HDF modalities $(\mathrm{N}=375)$.

The highest correlation between the spectral data of the dialysate and the concentration of $\beta 2 \mathrm{M}$ was observed in the case of combined UV absorbance with the fluorescence. The best correlations between UV absorbance, the excitation/emission of spent dialysate and the concentration of the $\beta 2 \mathrm{M}$ in spent dialysate were selected using multiple regression analysis yielding a model including the following optical parameters; UV absorbance at $280 \mathrm{~nm}$, fluorescence Ex280/Em325 and Ex350/Em555 (adjusted R 0.958, accuracy $(\mathrm{BIAS} \pm \mathrm{SE}) 0.000 \pm 0.304, \mathrm{~N}=375)$.

The identity and Bland Altman plots of the calibration and the validation groups comparing $\beta 2 \mathrm{M}$ determined at the clinical laboratory (Lab) and predicted optically (Opt), can be seen in Figure 3. The concentration of $\beta 2 \mathrm{M}$ in the dialysate for both groups was calculated with the algorithm, derived from regression data of the calibration group using optical parameters showing the best correlation combination. The correlation coefficient 0.966 with the accuracy of $0.000 \pm 0.272 \mathrm{mg} / \mathrm{L}$ was achieved for the calibration group, and the correlation coefficient 0.953 with the accuracy of $0.061 \pm 0.340 \mathrm{mg} / \mathrm{L}$ was achieved for the validation group between the laboratory estimated $\beta 2 \mathrm{M}$ concentration in spent dialysate and the corresponding values predicted by the optical model, respectively. 

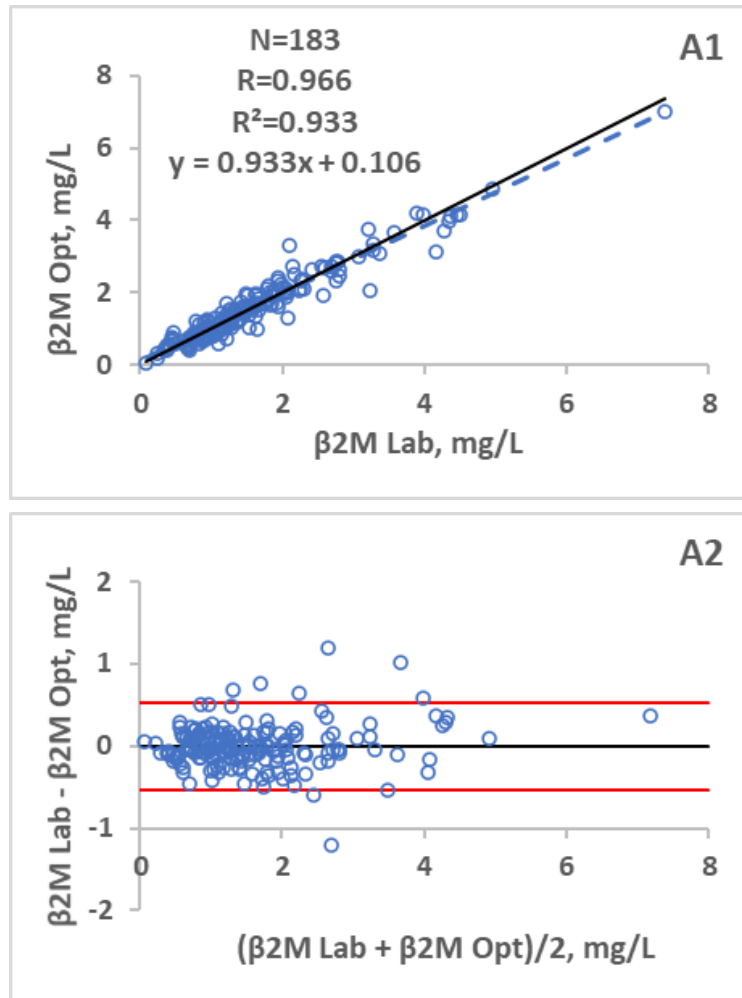
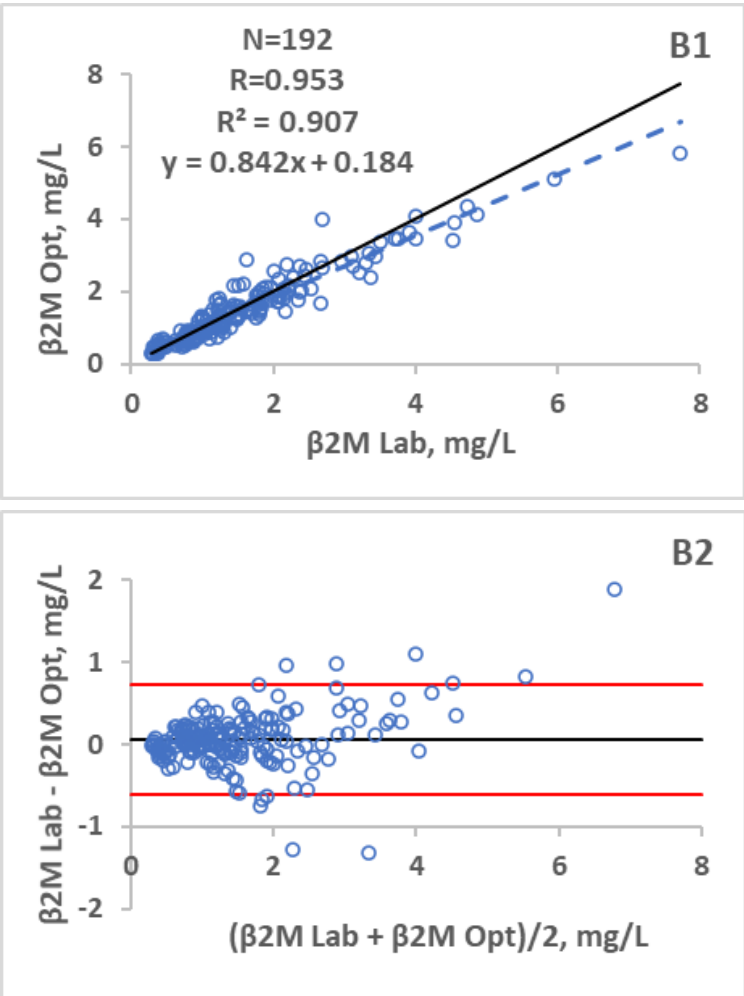

Figure 3. Identity plots of the $\beta 2 \mathrm{M}$ concentration in spent dialysate determined at the clinical laboratory (Lab) and predicted optically (Opt), and Bland-Altman plots of the differences between Lab and Opt concentrations. A-Calibration set, B-Validation set, 1-Regression plot, 2-Bland-Altman plot.

Figure 4 shows average changes of $\beta 2 \mathrm{M}$ concentration in the spent dialysate during the dialysis treatments estimated in parallel at the laboratory and optically for the validation set. The optically derived $\beta 2 \mathrm{M}$ concentration time profile corresponds well with the lab data.

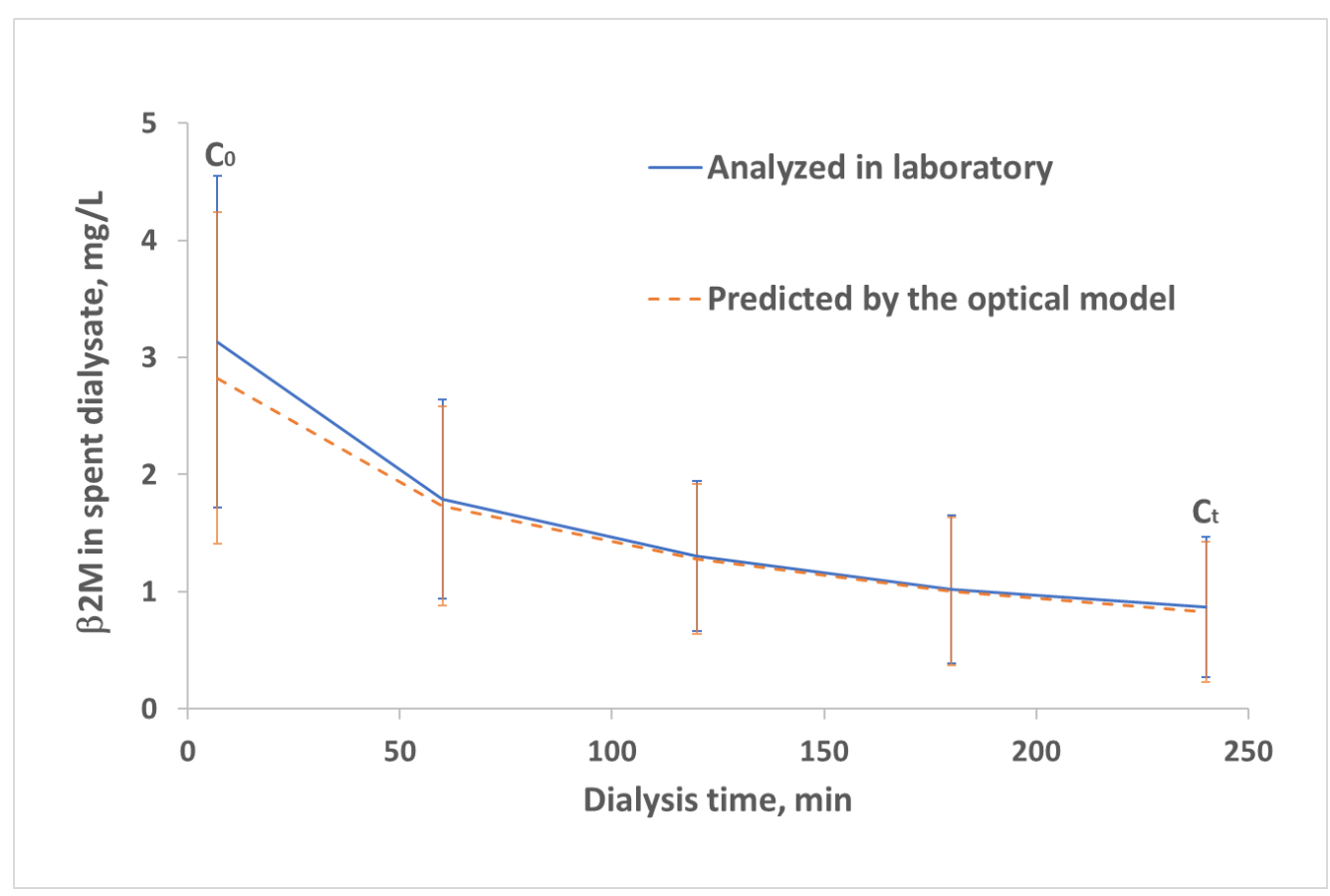

Figure 4. Time-series of changing $\beta 2 \mathrm{M}$ concentration (mean $\pm \mathrm{SD}$ ) in the spent dialysate during HDF dialysis sessions $(\mathrm{N}=29)$ for patients of the validation set. 
Corresponding clinical output for the validation set as the reduction ratio (RR) and total removed solute (TRS) values for $\beta 2 \mathrm{M}$ are presented in Table 1 using the best multiregression model (Figure 3 ) for $\beta 2 \mathrm{M}$ concentration prediction from the optical measurements. Optically and laboratory estimated values of RR and TRS were not statistically different ( $p>0.34$ and $p>0.35$, respectively).

Table 1. Clinical output of $\beta 2 \mathrm{M}$ removal by HDF dialysis as the average reduction ratio (RR) and the total removed solute (TRS) for the validation set.

\begin{tabular}{cccccc}
\hline $\begin{array}{c}\text { Clinical } \\
\text { Parameter }\end{array}$ & $\begin{array}{c}\beta 2 M \text { Lab } \\
\text { Mean } \pm \text { SD }\end{array}$ & $\begin{array}{c}\beta 2 M \text { Opt } \\
\text { Mean } \pm \text { SD }\end{array}$ & $\boldsymbol{p}$ & Accuracy (BIAS \pm & $\begin{array}{c}\text { Pearson } \\
\text { SE) }\end{array}$ \\
\hline RR $(\%, \mathrm{~N}=31)$ & $73.37 \pm 10.39$ & $72.06 \pm 7.77$ & 0.35 & $-1.31 \pm 5.41$ & 0.894 \\
TRS $(\mathrm{mg}, \mathrm{N}=33)$ & $234.5 \pm 72.8$ & $228.6 \pm 83.9$ & 0.35 & $-5.95 \pm 36.09$ & 0.904 \\
\hline
\end{tabular}

\subsection{UV and Fluorescence Spectra of the MM Fraction}

Figure 5 shows the average UV spectra measured as the difference between untreated spent dialysate samples and filtrates, containing solutes $<1 \mathrm{kDa}$ of the corresponding dialysate from standard HDF (stHDF) and low flux HD (LF HD) modalities (see Table 4 for dialysis settings). The most noticeable difference in UV absorbance referable to compounds with $\mathrm{MW}>1 \mathrm{kDa}$ seems to be in the wavelength region of 210-230 nm. Differences between the spectra of dialysate and corresponding filtrates, referable to compounds with MW $>1 \mathrm{kDa}$, were considered as characteristics of "MM fraction" hereinafter.

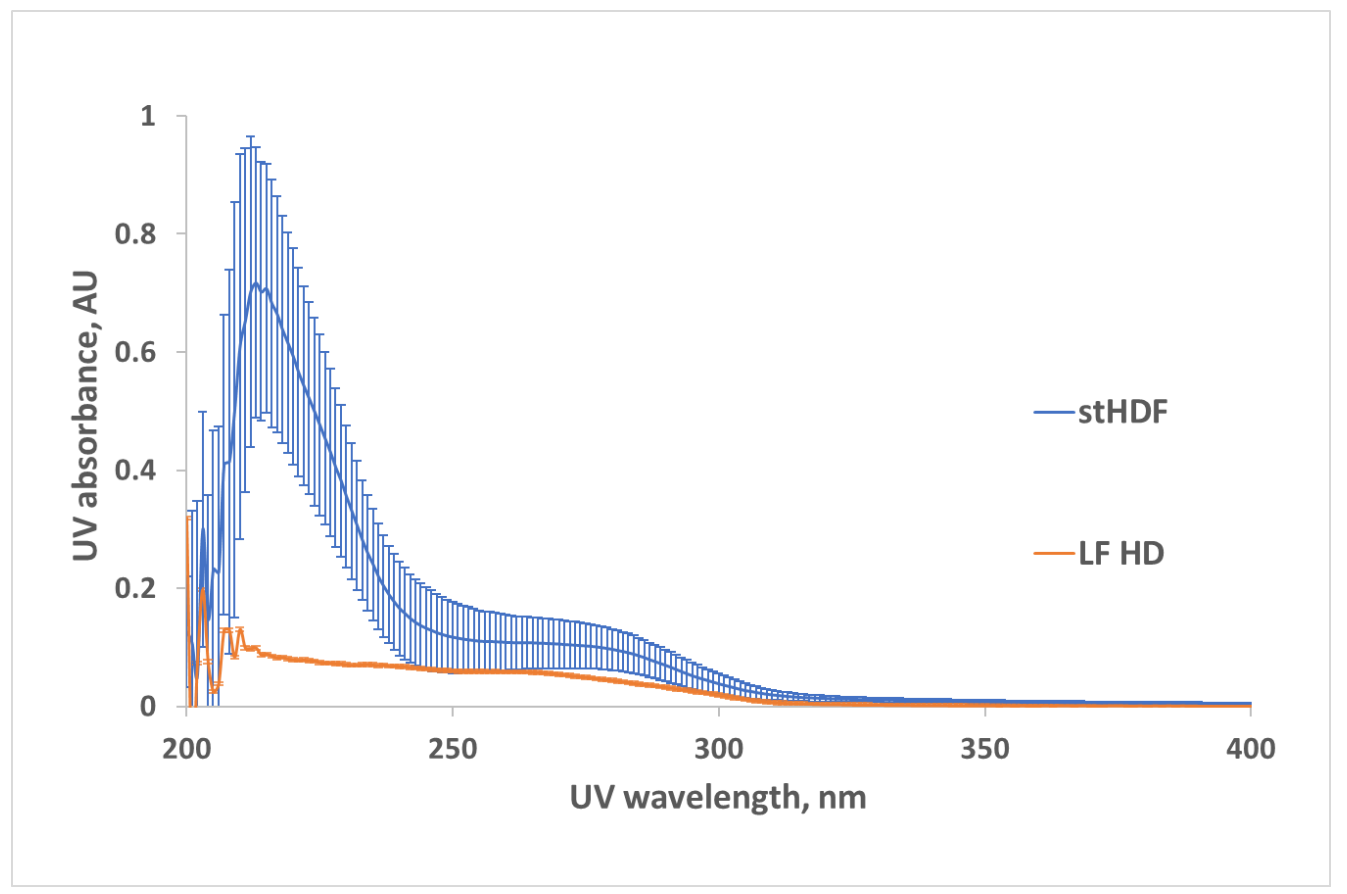

Figure 5. UV spectra (mean $\pm S D, N=9$ ) of middle molecule (MM) fractions of 7 min dialysate from low flux HD (LF HD) and standard HDF (stHDF) modality. The untreated dialysate was measured against corresponding filtrate containing solutes $<1 \mathrm{kDa}$ for a subset of samples.

Figure 6 shows the interrelationship between UV absorbance of untreated spent dialysate samples and corresponding filtrates, containing solutes $<1 \mathrm{kDa}$, from LF HD and stHDF modalities. The very high $\mathrm{R}^{2}$ value indicates that variation between optical signals of dialysate samples and corresponding filtrates, caused by the MM fraction, is negligible in the UV region $>230 \mathrm{~nm}$. 


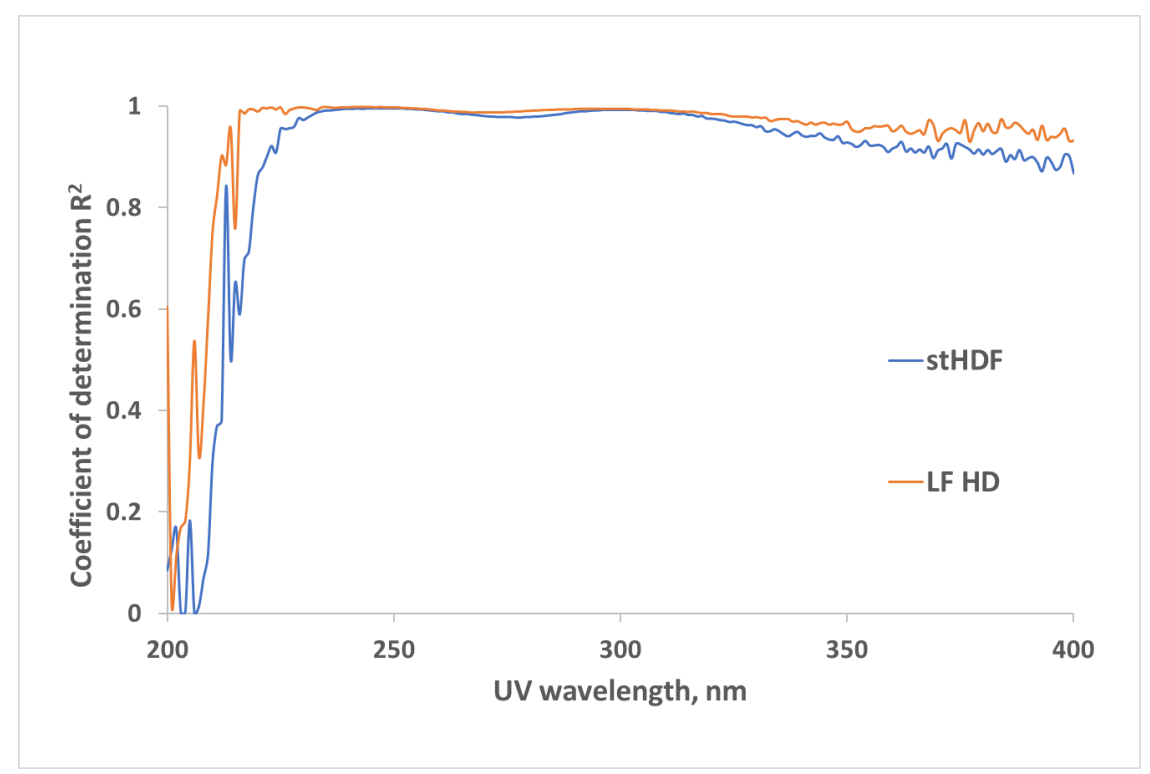

Figure 6. Correlation between UV-absorbance of untreated spent dialysate samples and UV-absorbance of corresponding filtrates, containing solutes $<1 \mathrm{kDa}$, from LF HD and the stHDF modalities sampled 7 min after the start of the dialysis from a subset of samples $(\mathrm{N}=17)$.

The mean fluorescence emission spectra of MM fractions with characteristic wavelengths of excitation, where the largest difference between MM fractions of LF HD and stHDF can be seen, are shown in Figure 7. Emission wavelengths are presented starting with the lowest meaningful excitation wavelength (i.e., for Ex220 nm emission starts from $230 \mathrm{~nm}$; for Ex280 nm Em starts from $290 \mathrm{~nm}$, and for Ex350 nm Em starts from $360 \mathrm{~nm}$ ). The predominant maximum emission of the expected MM fraction is evident in the wavelength region Ex280/Em325-335 nm. The fluorescence characteristic to advanced glycation end-products (AGEs) Ex350/Em430-550 nm is present in Figure 7, but with 10 times weaker intensity compared to fluorescence at Ex280/Em325-335 nm.

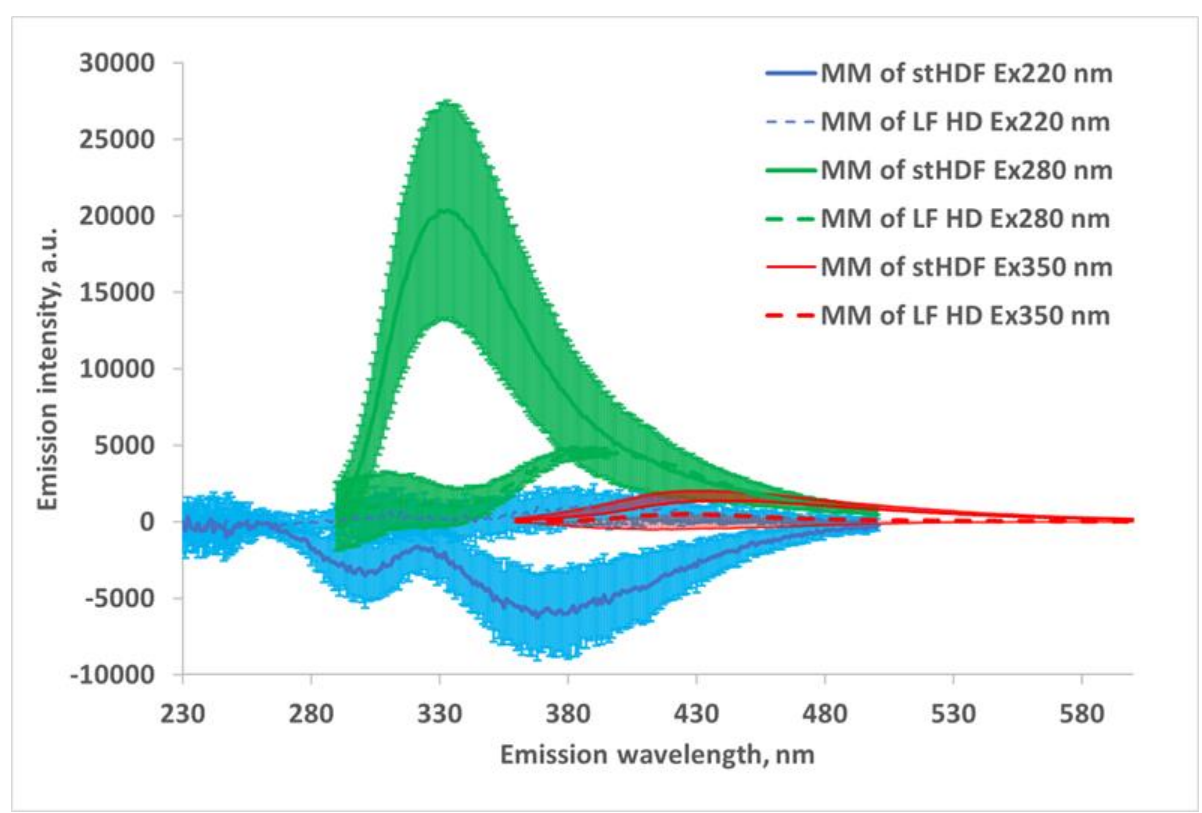

Figure 7. Fluorescence emission spectra (mean $\pm \mathrm{SD}, \mathrm{N}=17$ ) of $\mathrm{MM}$ fractions of dialysate measured as the difference between untreated dialysate and corresponding filtrates, containing solutes $<1 \mathrm{kDa}$, from LF HD and the stHDF modalities sampled $7 \mathrm{~min}$ after the start of the dialysis at some characteristic wavelengths from a subset of samples. 
For a subset of the stHDF samples collected 7 min after the start ( $\mathrm{N}=17), \mathrm{MM}$ fraction contributed on average $26.09 \pm 6.68 \%$ at Ex280/Em325 nm to overall fluorescence of the spent dialysate.

Figure 8 shows that the correlation between the optical signals of dialysate samples and corresponding filtrates is lowest in the wavelength region Ex280/Em320-330 nm due to removal of the MM fraction by filtration. This coincides with the predominant maximum emission region of the MM fraction in Figure 7. The lowest correlation is seen at Ex280/Em325 nm, with the coefficient of determination $R^{2}$ equal to 0.76 .

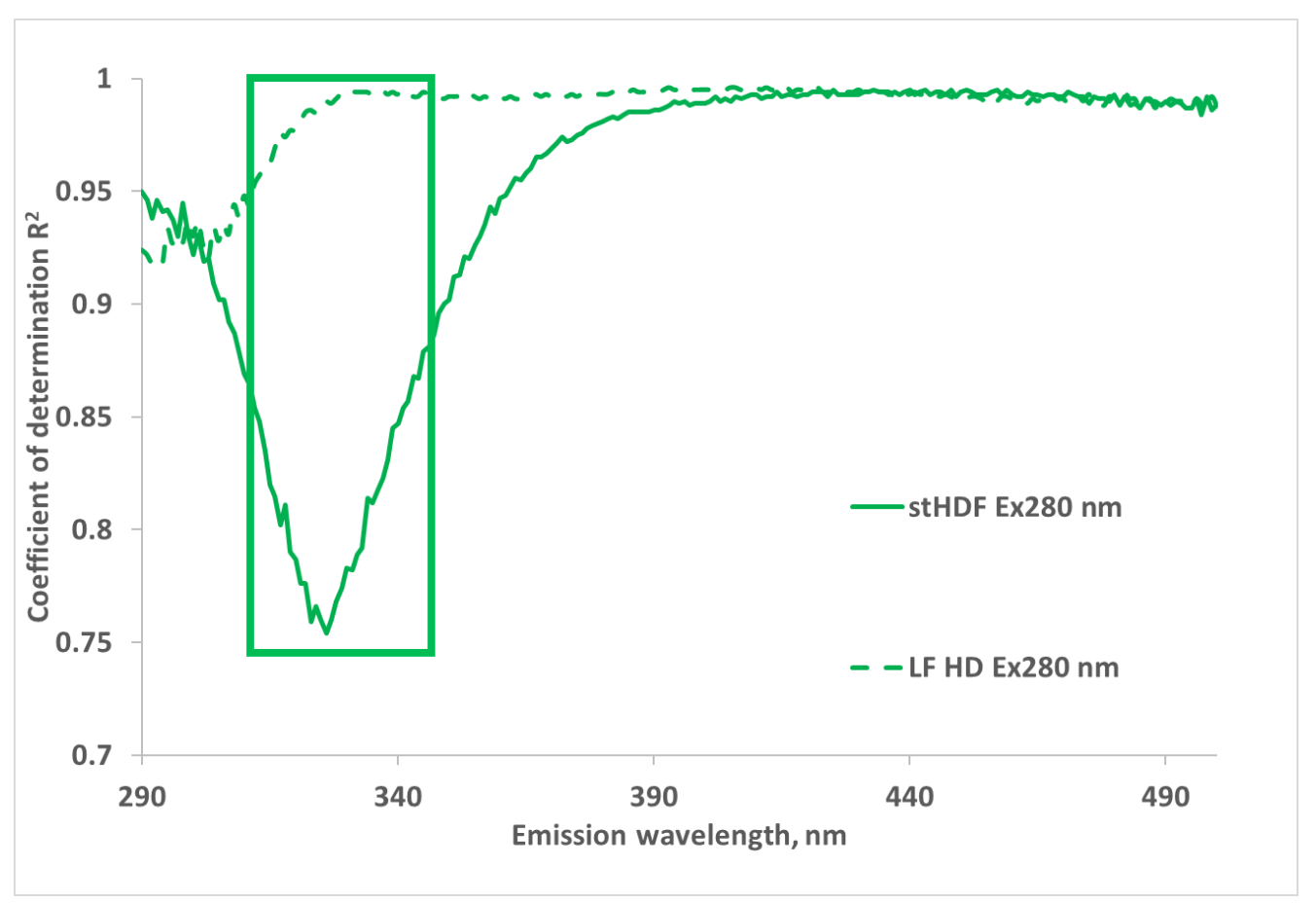

Figure 8. Correlation between fluorescence emission spectra of untreated spent dialysate and corresponding filtrates, containing uremic solutes $<1 \mathrm{kDa}$, from LF HD and the stHDF modalities sampled 7 min after the start of the dialysis at Ex280 $\mathrm{nm}$ from a subset of samples $(\mathrm{N}=17)$. Emission region with the highest correlation between $\beta 2 \mathrm{M}$ in the spent dialysate, used in the final regression model, is marked with a rectangle.

\section{Discussion}

The main findings of the study were: (1) concentration of MM uremic toxin $\beta 2 \mathrm{M}$ in spent dialysate can be assessed using the UV absorbance and fluorescence of the spent dialysate; (2) $\beta 2 \mathrm{M}$ concentration prediction from the optical measurements can be used for intradialytic $\beta 2 \mathrm{M}$ removal assessment as the RR and the TRS; (3) the main contributions to the optical signal of the MM fraction arise apparently from the fluorescence of tryptophan (Trp) in small proteins and peptides and the fluorescence of AGEs, whereas UV absorbance of the peptide bond and aromatic side chains of amino acids seems to have a smaller contribution.

Strong correlation and high accuracy were achieved in comparing the biochemically and optically estimated concentration of the MM uremic toxin $\beta 2 \mathrm{M}$ in spent dialysate using multiple regression analysis based on the data from all three HDF modalities ( $R$ value 0.966 and 0.953 , accuracy $0.000 \pm 0.272 \mathrm{mg} / \mathrm{L}$ and $0.061 \pm 0.340 \mathrm{mg} / \mathrm{L}$ for the calibration and the validation group, respectively). This enabled visualizing the changing $\beta 2 \mathrm{M}$ concentration in the spent dialysate during dialysis (Figure 4 ) and calculating the intradialytic $\beta 2 \mathrm{M}$ removal by HDF dialysis as RR and TRS from the optical signal (Table 1). The biochemically and optically assessed RR and TRS values were not statistically different $(p>0.34$ and $p>0.35$, respectively). Although the removal of $\beta 2 \mathrm{M}$ is limited by intercompartmental mass transfer, an RR of $68 \pm 2 \%$ was achieved in an earlier study of 10 patients with HDF in 
the post-dilution mode, calculated from pre- and post-treatment serum levels of $\beta 2 \mathrm{M}$ [33]. Our result of an optically estimated RR of $72.06 \pm 7.77 \%$ is comparable, considering that two modalities besides the standard HDF were aimed to achieve the maximal removal of middle molecules in our settings. A mean total single session removal of $\beta 2 \mathrm{M} 204.9 \pm 53.4 \mathrm{mg}$ was observed by Brunati et al., using standard high-flux bicarbonate dialysis [34], which is similar to the value $228.6 \pm 83.9 \mathrm{mg}$, achieved in this work using optical assessment technology combined with the total dialysate collection.

A comparison of both UV absorbance and fluorescence spectra of untreated HDF dialysate with corresponding filtrates, containing solutes $<1 \mathrm{kDa}$ (Figures 5 and 7), as well as the corresponding comparison of HDF and LF HD spent dialysate strongly supports the idea that optical properties of dialysate provide a potential for on-line monitoring of eliminating not only small and protein-bound molecules, but also middle molecule uremic toxins from the blood of ESKD patients [29-31]. The highest absorbance in the short wavelength region of UV light could be expected in the light of present knowledge about the peptide nature and amino acid composition of the MM uremic toxins [35]. The most widely used features of the absorbance spectra of proteins are attributed to chromophores present in the sidechains of aromatic amino acids like Trp around $280 \mathrm{~nm}$ $\left(\varepsilon \sim 5600 \mathrm{M}^{-1} \mathrm{~cm}^{-1}\right)$, tyrosine around $275 \mathrm{~nm}\left(\varepsilon \sim 1420 \mathrm{M}^{-1} \mathrm{~cm}^{-1}\right)$ and phenylalanine around $257 \mathrm{~nm}\left(\varepsilon \sim 197 \mathrm{M}^{-1} \mathrm{~cm}^{-1}\right)$ [36]. Our results from LF and stHDF modalities (Figure 6) confirm that the MM fraction does not have considerable contribution to the overall UV absorbance of spent dialysate in relation to other chromophores in spent dialysate [12] at corresponding wavelengths. The peptide bond in proteins has a strong absorbance at around $190 \mathrm{~nm}\left(\varepsilon \sim 7000 \mathrm{M}^{-1} \mathrm{~cm}^{-1}\right)$ and a weaker absorbance between 210 and $220 \mathrm{~nm}\left(\varepsilon \sim 100 \mathrm{M}^{-1} \mathrm{~cm}^{-1}\right)$ [37]. As dialysate has a very high absorbance below $230 \mathrm{~nm}[38,39]$, and upper absorbance measurement limit of a spectrophotometer was exceeded for some of the samples, which caused noisy data below $230 \mathrm{~nm}$; the cuvette with a shorter optical path length or dilution of spent dialysate samples must be used for a more detailed search of usability of this UV absorbance region for the assessment of MM removal by dialysis as it enables distinguishing the variation caused by the noise and MM fraction more clearly.

The abovementioned three amino acids are mainly responsible for the inherent fluorescence properties of proteins, with Trp being the dominant intrinsic fluorophore in proteins (Table 2). The deep negative emission of the peak at Ex220/Em370-380 nm (Figure 7) is evidently caused by excitation light absorbance in the short UV wavelength region (so-called inner filter effect) observed also in many other mixtures of fluoro- and chromophores in solutions $[40,41]$.

Table 2. The fluorescent properties of aromatic amino acids in water at neutral $\mathrm{pH}$ [42].

\begin{tabular}{ccccc}
\hline Amino Acid & $\begin{array}{c}\text { Excitation } \\
\text { Wavelength } \mathbf{( n m )}\end{array}$ & $\begin{array}{c}\text { Emission } \\
\text { Wavelength } \mathbf{( n m )}\end{array}$ & $\begin{array}{c}\text { Bandwidth } \\
\text { (nm) }\end{array}$ & $\begin{array}{c}\text { Quantum } \\
\text { Yield }\end{array}$ \\
\hline Tryptophan & 295 & 353 & 60 & 0.13 \\
Tyrosine & 275 & 304 & 34 & 0.14 \\
Phenylalanine & 260 & 282 & - & 0.02 \\
\hline
\end{tabular}

In addition to the intrinsic fluorescence of these amino acids, a set of UV-absorbing and fluorescent post-translational modifications, including AGEs, has been described, where free amino groups of aliphatic amino acids are involved [43-46]. Such types of chromoand fluorophores are known to accumulate in chronic hemodialysis patients [47-50] and have a large variety of toxic effects for dialysis patients [51]. Only a small part of AGEs has a fluorescence excitation region in the usual absorption wavelength of proteins [46]. Still, the fluorescence of deproteinized serum, specific to AGEs (Ex370/Em440 nm), has been found to predict mortality in hemodialysis patients [52]. AGE pentosidine, which is a crosslink between arginine and lysine residues in proteins [53], has an absorption at $335 \mathrm{~nm}$ and a maximum emission at about 375-385 nm [54,55]. Among other typical fluorescent 
AGEs, argpyrimidine has high absorbance between 320 and $335 \mathrm{~nm}$, and a fluorescence emission maximum of about $400 \mathrm{~nm}$ [56]; the vesperlysine A, a crosslink between two lysine residues, has a maxima of absorption at 302 and $263 \mathrm{~nm}$ and maxima of emission at 380 and $440 \mathrm{~nm}$ [57]. The crossline, another crosslink between two lysine residues, has an emission maximum at $440 \mathrm{~nm}$ with excitation at $380 \mathrm{~nm}$ [56]. The human $\beta 2 \mathrm{M}$ modified by glycation is the major component of hemodialysis-associated amyloidosis and has an emission maximum at $450 \mathrm{~nm}$ with an excitation at $360 \mathrm{~nm}$ [58]. This coincides with the higher emission intensity above $400 \mathrm{~nm}$ of an MM fraction at an excitation of $350 \mathrm{~nm}$ measured in the spent dialysate from HDF (Figure 7). Moreover, the fluorescence in the same Ex/Em wavelength region exhibited a high degree of correlation with the concentration of $\beta 2 \mathrm{M}$ in our experiments (Figure 2), with the highest correlation at even higher emission wavelengths of up to $555 \mathrm{~nm}$. This agreement indicates that the fluorescence of AGEs may be the main source of fluorescence of the MM fraction of spent dialysate at least in the longer excitation wavelength region, where aromatic amino acids of MM fraction do not exhibit fluorescent properties. An emission maximum around $450 \mathrm{~nm}$ as well as a clear difference between HD and HDF dialysate in this region (Figure 7) supports the essential role of AGEs in the formation of the fluorescence of the MM fraction. Some shifts in highest correlation values between $\beta 2 \mathrm{M}$ and emission toward longer wavelengths above $450 \mathrm{~nm}$ (Figure 2) may be explained to some degree by the energy transfer between different fluorophores in the dialysate (e.g., Förster resonance energy transfer) $[59,60]$ as well as by re-absorbance by different fluorophores and re-emission in longer wavelength regions.

Some weak emissions of non-modified $\beta 2 \mathrm{M}$ can be achieved with excitation at $220 \mathrm{~nm}$, but such emissions of spent dialysate were found to be independent of the concentration of $\beta 2 \mathrm{M}$ in the dialysate leading to the conclusion that the $\beta 2 \mathrm{M}$ in spent dialysate cannot be directly monitored by spectrophotometric measurements [61]. Our spectra of the MM fraction of dialysate (Figure 7) confirm this statement regarding that neither the emission of glycated nor normal $\beta_{2} \mathrm{M}$ are evidently dominant in the total fluorescence of spent dialysate at shorter excitation wavelengths when not corrected for the primary inner filter effect. However, correction of the inner filter effect is crucial to achieve a linear relationship between the fluorophore's concentration and fluorescence in highly absorbing samples $[40,41]$ such as spent dialysate $[38,39]$.

The most essential role in the formation of fluorescence of MM fraction seems to originate from the emission region $320-340 \mathrm{~nm}$, with the average maximum at $332 \mathrm{~nm}$, if excited at $280 \mathrm{~nm}$ (Figures 7 and 8), which is common for fluorescence of Trp residues in hydrophobic environment of peptides and proteins [62]. This is also close to intrinsic Trp fluorescence of $\beta 2 \mathrm{M}$ under native condition with the peak at $\sim 337 \mathrm{~nm}$ [63]. MM fractions contributed on average $26.09 \pm 6.68 \%$ to the overall fluorescence of spent dialysate at Ex280/Em325 nm at the beginning of dialysis from the stHDF modality. Interestingly, for the same dataset, the correlation between optical signals of dialysate samples and the corresponding filtrates, containing solutes $<1 \mathrm{kDa}$, was lowest in the wavelength region Ex280/Em320-330 nm due to the removal of the MM fraction $\left(R^{2}=0.76\right)$, which confirms the high contribution of the MM fraction to the overall fluorescence signal of spent dialysate. In addition, a good correlation was found between the emission intensity at Ex280/Em325 nm, corrected for the inner filtering effect, and the concentration of $\beta 2 \mathrm{M}$ in spent dialysate from different HDF modalities and timepoints $\left(R^{2}=0.838, N=375\right)$.

Apart from aromatic amino acids, pyridoxin and typical enzyme cofactors such as pyridoxal phosphate, pyridoxamine phosphate, nicotinamide adenine dinucleotide and flavin adenine dinucleotide are listed as the main natural intrinsic fluorophores in living tissues [42], which evidently may be adsorbed to proteins with the dimensions of "middle molecules".

In future, specific MM uremic toxins behind the optical properties of MM fraction could be identified by separating the MM fraction to individual chromo- and fluorophores. This could provide additional information about differences between patients and validate the method more extensively. 


\section{Conclusions}

The present work suggests that multicomponent regression analysis proved to be a useful tool for the combination of absorbance and fluorescence at different wavelength regions for concentration and elimination assessment of the $\mathrm{MM}$ uremic toxin $\beta 2 \mathrm{M}$ during dialysis treatment. Including more independent variables (e.g., patient- and diagnosis-specific) into the multiparameter regression analysis may be the next step. The main contributors in the formation of optical properties of the MM fraction are apparently the fluorescence of Trp in small proteins and peptides and the fluorescence of AGEs; whereas UV absorbance of peptide bond and aromatic side chains of amino acids seems to have smaller contribution. Complicated mutual influences of chromophores and fluorophores in dialysate do not allow to attribute distinct excitation/emission wavelength pairs to specific fluorophores in the complex mixture of chromo- and fluorophores present in dialysate. Some presumptive assessments resulting from the phenomenon of the correlations found in this work allow evaluating the optical technology as promising for on-line optical monitoring of eliminating not only $\beta 2 \mathrm{M}$ but also all of the MM fraction during dialysis treatment.

\section{Materials and Methods}

In total, 22 ESKD patients were enrolled into the study from the Centre of Nephrology at the North Estonia Medical Centre, Tallinn, Estonia. The study was approved by the Tallinn Medical Research Ethics Committee in Estonia (decision no. 2205, 27. Dec. 2017) and conducted in accordance with the Declaration of Helsinki. Inclusion criteria were the following: over 18 years old patients on chronic hemodialysis, HD procedures via $\mathrm{AV}$ fistula or graft (catheters were not used) for $4 \mathrm{~h}$ thrice weekly, blood access capable to manage blood flow of at least $300 \mathrm{~mL} / \mathrm{min}$, absence of clinical signs of infection or other active acute clinical complications and an estimated life expectancy over 6 months. Clinical data of the participants monitored for a total of $88 \mathrm{HD}$ sessions is presented in Table 3.

Table 3. Clinical data of the end stage kidney disease (ESKD) patients. Numerical values are given as a mean \pm SD or as a median and interquartile range (Q1-Q3).

\begin{tabular}{|c|c|}
\hline Entity of the Data & Specification \\
\hline Cause of ESKD & $\begin{array}{l}\text { Diabetes (4); Hypertension (8); Glomerulonephritis (3); } \\
\text { Tubulointerstitial nephritis (3); Renal carcinoma (2); Other (2) }\end{array}$ \\
\hline Age (years) & $55 \pm 17$ \\
\hline Gender & $\mathrm{M}(17), \mathrm{F}(=5)$ \\
\hline Race, Caucasian $(\%)$ & 100 \\
\hline BMI, $\mathrm{kg} / \mathrm{m}^{2} \mathrm{a}$ & $26.8 \pm 5.8$ \\
\hline $\mathrm{BW}, \mathrm{kg}^{\mathrm{a}}$ & $81.5 \pm 21.3$ \\
\hline Ultrafiltration volume, $\mathrm{mL}$ & $2565 \pm 1190$ \\
\hline & $0(14$ patients $)$ \\
\hline Urinary volume, mL & 700 (335-825) (8 patients) \\
\hline Serum total protein, $\mathrm{g} / \mathrm{L}$ & $62.8 \pm 5.5$ \\
\hline Hematocrit, \% ${ }^{a}$ & $34.4(3.5)$ \\
\hline Serum calcium, mmol/ $\mathrm{L}^{\mathrm{a}}$ & $2.25(0.16)$ \\
\hline Serum phosphorus, $\mathrm{mmol} / \mathrm{L}^{\mathrm{a}}$ & $1.92(1.63-2.29)$ \\
\hline Serum parathyroid hormone, $\mathrm{pmol} / \mathrm{L}^{\mathrm{a}}$ & $28.7(16.8-41.9)$ \\
\hline Dialysis access & native fistula (15); graft (7) \\
\hline Dialysis vintage, months ${ }^{\text {a }}$ & $23(11-83)$ \\
\hline $\mathrm{spKt}_{\text {/Vurea }}{ }^{\mathrm{a}}$ & $1.47(1.23-1.67)$ \\
\hline
\end{tabular}

Abbreviations: $\mathrm{M}$-male; F-female; BMI—body mass index; BW—body weight; spKt/V—single-pool criterion of the dose of dialysis, stHDF-standard HDF. ${ }^{\text {a }}$ Based on data of stHDF.

Each patient was observed during four midweek dialysis sessions, using Fresenius 5008 dialysis machines (Fresenius Medical Care, Bad Homburg v. d. Höfe, Germany). In order to include large variety of treatment settings, the following dialysis modalities, dialyzers and machine settings were applied (Table 4): (1) standard HDF dialysis with 
standard settings (stHDF), as previously prescribed for the patient in routine clinical care. This provided a baseline and introduced patients more smoothly into the study; (2) low flux HD (LF HD) with minimal dialysis settings to provide conditions for minimal uremic toxin removal; (3) medium HDF with maximum dialyzer surface area and highest dialysate (d) blood (b) flow ratio (Qd/Qb); (4) high HDF with maximum dialysis settings in terms of dialyzer surface area, dialysate and blood flow, and the substitution volume expected to increase removal of MM.

Table 4. Dialysis treatment settings of hemodiafiltration (HDF) and hemodialysis (HD). Numerical values are given as mean \pm SD.

\begin{tabular}{|c|c|c|c|c|}
\hline Entity of the Data & $\begin{array}{c}\text { Standard } \\
\text { HDF }\end{array}$ & $\begin{array}{c}\text { Low Flux } \\
\text { HD }\end{array}$ & $\begin{array}{l}\text { Medium } \\
\text { HDF }\end{array}$ & $\begin{array}{l}\text { High } \\
\text { HDF }\end{array}$ \\
\hline Volume substituted (Vs, L) & $21.1 \pm 3.1$ & $0 \pm 0$ & $15.3 \pm 1.4$ & $25.3 \pm 2.8$ \\
\hline Dialysis time, min. & 240 & 240 & 240 & 240 \\
\hline Blood flow, mL/min (Qb) & $300.8 \pm 12.7$ & $200 \pm 0$ & $299.7 \pm 1.0$ & $364.2 \pm 27.1$ \\
\hline Dialysate flow, $\mathrm{ml} / \mathrm{min}$ (Qd) & $470.8 \pm 105.4$ & $300 \pm 0$ & $799.8 \pm 0.9$ & $800.0 \pm 0.0$ \\
\hline Dialyzer area ${ }^{\mathrm{a}}, \mathrm{m}^{2}$ & $2.0 \pm 0.2$ & $1.5 \pm 0.0$ & $2.2 \pm 0.0$ & $2.2 \pm 0.0$ \\
\hline Number of dialyses $(\mathrm{N})$ & 22 & 22 & 22 & 22 \\
\hline
\end{tabular}

a Specification of dialyzers: Standard: FX800 ( $=8)$, FX1000 ( $\mathrm{N}=14)$, Low flux: Lo15 ( $\mathrm{N}=22)$, Medium: FX1000 (N = 22), High: FX1000 $(\mathrm{N}=22)$. All dialyzers had polysulfone-based membranes with the following effective membrane area: $1.8 \mathrm{~m}^{2}\left(\right.$ Helixone $\left.^{\circledR}, \mathrm{FX} 800\right), 2.2 \mathrm{~m}^{2}$ (Helixone ${ }^{\circledR}$, FX1000), $1.5 \mathrm{~m}^{2}$ (Amembris ${ }^{\circledR}$, Xevonta Lo 15).

Spent dialysate samples were taken from the dialysate outlet of the dialysis machine before dialysis, at 7, 60, 120 and $180 \mathrm{~min}$ after the start of the session and at the end of the session (240 $\mathrm{min})$. In addition, the waste dialysate was collected into a large tank during the whole procedure. After the end of the procedure, the dialysate collection tank was weighed, and one sample was taken from it after careful stirring. All dialysate samples were divided into three sets: the first set of samples were directly sent to a clinical laboratory for analysis of $\beta 2 \mathrm{M}$; another two sets of samples were separated for the analytical laboratory analyses. Prior to transportation, the samples were processed as follows: (A) spent dialysate samples for the clinical laboratory were collected into $120 \mathrm{~mL}$ Becton Dickinson Vacutainer urine collection cups (Franklin Lakes, NJ, USA) and drawn thereafter into the Becton Dickinson Vacutainer SST II Advanced 5 mL (Franklin Lakes, NJ, USA) vacuum tubes; (B) one set of samples for analytical chemistry analysis were transported into the lab in $120 \mathrm{~mL}$ Becton Dickinson Vacutainer urine collection cups; $(C)$ the third set of samples were subjected to centrifugation. $12 \mathrm{~mL}$ of dialysate were loaded into the centrifugal filter tube with MW cut-off limit 1 kDa (Pall Laboratory Macrosep ${ }^{\circledR}$ type MAP001C37, Pal Corp., Ann Arbor, MI, USA) and centrifuged at $37^{\circ} \mathrm{C}$ for $40 \mathrm{~min}$ with the speed of $5000 \mathrm{rpm}(2375.75 \times g$, type 2-16 KL centrifuge with the rotor 11,192 from the Sigma Laborzentrifugen GmbH, Osterode am Harz, Germany). Filtrates were pipetted into standard laboratory vials with Teflontightened screw caps and transported into the lab together with the non-filtered samples.

The set $\mathrm{A}$ of samples was analyzed for $\beta 2 \mathrm{M}$ by the clinical laboratory (SYNLAB Eesti OÜ, Tallinn, Estonia) using standard sandwich type immunochemical system "Immulite 2000 Beta-2 Microglobulin" (Siemens Healthineers AG, Erlangen, Germany). Sets B and $\mathrm{C}$ of samples were subjected to optical analyses during the day of sampling at room temperature, as follows: UV spectra were recorded with the UV-3600 spectrophotometer (Shimadzu, Kyoto, Japan) in the wavelength range of 190-400 nm with the increment of $1 \mathrm{~nm}$ using a quartz cuvette with optical path length of $10 \mathrm{~mm}$. An untreated pure dialysis buffer, sampled from the outflow of the dialysis machine prior to switching on the blood flow, was used as the reference solution in UV measurements (separately for each dialysis session) or the filtrate of the measurement of dialysate for the same patient. Fluorescence spectra were recorded with the spectrofluorometer RF-6000 (Shimadzu, Kyoto, Japan) using the excitation wavelength range of $200-400 \mathrm{~nm}$ with the increment of $10 \mathrm{~nm}$ and the emission wavelength range of 210-600 $\mathrm{nm}$ with the increment of $1 \mathrm{~nm}$. The bandwidths of $5 \mathrm{~nm}$ were used in both monochromators and the used quartz cuvette had an optical 
path length of $4 \mathrm{~mm}$. Differences between the spectra of the dialysate and corresponding filtrates, referable to compounds with $\mathrm{MW}>1 \mathrm{kDa}$, were considered as characteristics of the "MM fraction" and their possible biochemical origin was examined based on data available in the literature. Additionally, a regression analysis was used to analyze the variation of optical signals at different wavelengths, caused by the MM fraction, when comparing the spectra of dialysate samples and corresponding filtrates. Correction of emission intensity in relation to inner filtering of the excitation beam was used in the case of excitation at $280 \mathrm{~nm}$ when included into the final regression model [40,41].

Forward stepwise regression was used to obtain regression models for the assessment of the $\beta 2 \mathrm{M}$ concentration through optical parameters of spent dialysate. Independent variables included UV absorbance and fluorescence with selected excitation/emission wavelength pairs as specified below. The final choice of the best combination of optical parameters was validated by dividing HDF data into a calibration set $(50 \%$ of the material, i.e., 11 patients with even number of registration, $33 \mathrm{HDF}$ sessions) and a validation set ( $50 \%$ of the material, 11 patients with odd number of registration, $33 \mathrm{HDF}$ sessions).

Systematic error (BIAS) was calculated for the models as follows:

$$
\mathrm{BIAS}=\frac{\sum_{i=1}^{\mathrm{N}} e_{i}}{\mathrm{~N}}
$$

where $e_{i}$ is the $i$-th residual (difference between the lab and modelled $\beta 2 \mathrm{M}$ ) and $\mathrm{N}$ is the number of observations [64].

Standard error of performance corrected for BIAS was calculated for the two models as follows [64].

$$
\mathrm{SE}=\sqrt{\frac{\sum_{i=1}^{\mathrm{N}}\left(e_{i}-\mathrm{BIAS}\right)^{2}}{\mathrm{~N}-1}}
$$

Removal of $\beta 2 \mathrm{M}$ during dialysis sessions was described by a reduction ratio \% (RR) in dialysate:

$$
\mathrm{RR}=\frac{\mathrm{C}_{0}-\mathrm{C}_{\mathrm{t}}}{\mathrm{C}_{0}} \times 100 \%
$$

where $C_{0}$ is the concentration of $\beta 2 \mathrm{M}$ in a spent dialysate sample taken after $7 \mathrm{~min}$ from the start of the dialysis procedure and $C_{t}$ is the concentration of $\beta 2 \mathrm{M}$ in a spent dialysate sample taken at the end of the dialysis procedure.

The total removed solute (TRS) of $\beta 2 \mathrm{M}$ was calculated based on the total dialysate collection (TDC) as follows:

$$
\mathrm{TRS}=\mathrm{C}_{\mathrm{T}} \times \mathrm{W}_{\mathrm{T}}
$$

where $C_{T}$ is the final substance concentration in the dialysate collection tank and $W_{T}$ is the weight of the dialysate collection tank [kg]. It was assumed that the average density of spent dialysate is $1.008 \pm 0.001 \mathrm{~kg} / \mathrm{L}$ [65]. Both RR and TRS were calculated based on $\beta 2 \mathrm{M}$ concentration in dialysate estimated in the laboratory as well as by the best optical multiparameter model. Excel MS 365 (Microsoft, Redmond, WA, USA) and MATLAB R2019b (MathWorks, Natick, MA, USA) software were used for statistical analyses. All results were assessed for possible errors and data conformity. Twenty-one data points from the total of 396 were omitted from the data set due to errors related to sample drawing, clinical laboratory analysis and due to self-tests of the HD machine. Individual differences in the laboratory and optically estimated results were examined using a Bland and Altman analysis [66], and a parametric paired t-test (two-tailed) was used to determine the statistical difference between laboratory and optical methods. A $p$-value of $<0.05$ was considered statistically significant. 
Author Contributions: Conceptualization, A.A., J.A., I.F., L.L., M.L., J.P., R.T.; data curation, J.P., J.A., K.L., L.L., R.T.; formal analysis, J.P., J.A., I.F., R.T.; funding acquisition: I.F.; investigation, J.P., A.A., J.A., K.L., L.L., R.T.; methodology, A.A., J.A., I.F., K.L., L.L., M.L., J.P., R.T.; project administration: J.A., M.L.; validation, J.A., J.P., and I.F.; visualization, J.P., and R.T.; writing-original draft preparation, J.P., R.T., A.A., J.A., I.F., L.L., M.L.; writing-review and editing, J.P., A.A., J.A., I.F., K.L., L.L., M.L., R.T.; All authors have read and agreed to the published version of the manuscript.

Funding: The research was funded partly by the European Union through the European Regional Development Fund H2020-SMEINST-2-2017, OLDIAS2-Online Dialysis Sensor Phase2 project, Grant Agreement nr 767572, the Estonian Ministry of Education and Research under institutional research financing, grant nr IUT 19-2, and by Estonian Centre of Excellence in IT (EXCITE) funded by European Regional Development Fund.

Institutional Review Board Statement: The study was conducted according to the guidelines of the Declaration of Helsinki, and approved by the Tallinn Medical Research Ethics Committee in Estonia (decision no. 2205, 27 December 2017).

Informed Consent Statement: Informed consent was obtained from all subjects involved in the study.

Data Availability Statement: Data sharing is not applicable due to legal and privacy issues.

Acknowledgments: The authors wish to thank all dialysis patients who participated in the experiments, and nurses at the Centre of Nephrology, North Estonia Medical Centre for assistance during the clinical experiments. The authors greatly acknowledge technical help of the students M. Alev, M. Lukner, L. Rannamäe and R. Toome in sample and data processing.

Conflicts of Interest: The authors declare no conflict of interest. The funders had no role in the design of the study; in the collection, analyses, or interpretation of data; in the writing of the manuscript, or in the decision to publish the results.

\section{References}

1. Tattersall, J.; Martin-Malo, A.; Pedrini, L.; Basci, A.; Canaud, B.; Fouque, D.; Haage, P.; Konner, K.; Kooman, J.; Pizzarelli, F.; et al. EBPG guideline on dialysis strategies. Nephrol. Dial. Transplant. 2007, 22, ii5-ii21. [CrossRef]

2. Tattersall, E.; Ward, R.; Canaud, B.; Blankestijn, P.J.; Bots, M.; Covic, A.; Davenport, A.; Grooteman, M.; Gura, V.; Hegbrant, J.; et al. Online haemodiafiltration: Definition, dose quantification and safety revisited. Nephrol. Dial. Transplant. 2013, 28, 542-550. [CrossRef]

3. Daugirdas, J.T.; Depner, T.A.; Inrig, J.; Mehrotra, R.; Rocco, M.V.; Suri, R.S.; Weiner, D.E.; Greer, N.; Ishani, A.; MacDonald, R.; et al. KDOQI Clinical Practice Guideline for Hemodialysis Adequacy: 2015 Update. Am. J. Kidney Dis. 2015, 66, 884-930. [CrossRef]

4. Gál, G.; Gróf, J. Continuous Uv Photometric Monitoring of the Efficiency of Hemodialysis. Int. J. Artif. Organs 1980, 3, 338-341. [CrossRef] [PubMed]

5. Fridolin, I.; Magnusson, M.; Lindberg, L.-G. Measurement of solutes in dialysate using UV absorption. BiOS 2001 Int. Symp. Biomed. Opt. 2001, 4263, 40-48. [CrossRef]

6. Fridolin, I.; Magnusson, M.; Lindberg, L.-G. On-Line Monitoring of Solutes in Dialysate Using Absorption of Ultraviolet Radiation: Technique Description. Int. J. Artif. Organs 2002, 25, 748-761. [CrossRef]

7. Uhlin, F.; Fridolin, I.; Magnusson, M.; Lindberg, L.-G. Dialysis dose (Kt/V) and clearance variation sensitivity using measurement of ultraviolet-absorbance (on-line), blood urea, dialysate urea and ionic dialysance. Nephrol. Dial. Transplant. 2006, 21, $2225-2231$. [CrossRef]

8. Castellarnau, A.; Werner, M.; Günthner, R.; Jakob, M. Real-time Kt/V determination by ultraviolet absorbance in spent dialysate: Technique validation. Kidney Int. 2010, 78, 920-925. [CrossRef] [PubMed]

9. Umimoto, K.; Tatsumi, Y.; Kanaya, H.; Jokei, K. Analysis of Uremic Substances in Dialysate by Visible Ultraviolet Spectroscopy; Springer: Berlin, Germany, 2007; pp. 3205-3207.

10. Umimoto, K.; Kanaya, Y.; Kawanishi, H.; Kawai, N. Measuring of Uremic Substances in Dialysate by Visible Ultraviolet Spectroscopy; Springer: Berlin, Germany, 2009; pp. 42-45.

11. Vasilevskiy, A.M.; Konoplev, G.A. Polycomponental monitoring of process of effluent dialyzate by a method of uf of spectrometry. Biotekhnosfera 2009. Available online: https://scholar.google.com/scholar?cluster=6506178806057926161 (accessed on 23 December 2020).

12. Arund, J.; Tanner, R.; Uhlin, F.; Fridolin, I. Do Only Small Uremic Toxins, Chromophores, Contribute to the Online Dialysis Dose Monitoring by UV Absorbance? Toxins 2012, 4, 849-861. [CrossRef] [PubMed]

13. Holmar, J.; Fridolin, I.; Uhlin, F.; Lauri, K.; Luman, M. Optical Method for Cardiovascular Risk Marker Uric Acid Removal Assessment during Dialysis. Sci. World J. 2012, 2012, 1-8. [CrossRef] [PubMed]

14. Tomson, R.; Fridolin, I.; Uhlin, F.; Holmar, J.; Lauri, K.; Luman, M. Optical measurement of creatinine in spent dialysate. Clin. Nephrol. 2013, 79, 107-117. [CrossRef] 
15. Enberg, P.; Fridolin, I.; Holmar, J.; Fernström, A.; Uhlin, F. Utilization of UV Absorbance for Estimation of Phosphate Elimination during Hemodiafiltration. Nephron 2012, 121, c1-c9. [CrossRef]

16. Holmar, J.; Uhlin, F.; Fernström, A.; Luman, M.; Jankowski, J.; Fridolin, I. An Optical Method for Serum Calcium and Phosphorus Level Assessment during Hemodialysis. Toxins 2015, 7, 719-727. [CrossRef] [PubMed]

17. Luman, M.; Jerotskaja, J.; Lauri, K.; Fridolin, I. Dialysis dose and nutrition assessment by optical on-line dialysis adequacy monitor. Clin. Nephrol. 2009, 72, 303-311. [CrossRef] [PubMed]

18. Uhlin, F.; Fridolin, I. Optical Monitoring of Dialysis Dose; Springer Science and Business Media LLC: New York, NY, USA, 2013; pp. 867-928.

19. Adimea Real-Time Monitoring Process. Available online: https://www.bbraun.com/content/dam/catalog/bbraun/ bbraunProductCatalog/S/AEM2015/en-01/b3/adimea.pdf (accessed on 23 December 2020).

20. Kt/v Measurement. Dialysis Dose Monitor Measuring the Delivered Dialysis Dose. Available online: http:/ / nikkisomedical. com/wp-content/uploads/2017/06/DDM_english_2013-03_vers04.pdf (accessed on 23 December 2020).

21. Arund, J.; Luman, M.; Uhlin, F.; Tanner, R.; Fridolin, I. Is Fluorescence Valid to Monitor Removal of Protein Bound Uremic Solutes in Dialysis? PLoS ONE 2016, 11, e0156541. [CrossRef]

22. Holmar, J.; Arund, J.; Uhlin, F.; Tanner, R.; Fridolin, I. Quantification of Indoxyl Sulphate in the Spent Dialysate Using Fluorescence Spectra. In Proceedings of the 1st World Congress on Electroporation and Pulsed Electric Fields in Biology, Medicine and Food \& Environmental Technologies, Portorož, Slovenia, 6-10 September 2011; pp. 45-48.

23. Holmar, J.; Uhlin, F.; Ferenets, R.; Lauri, K.; Tanner, R.; Arund, J.; Luman, M.; Fridolin, I. Estimation of removed uremic toxin indoxyl sulphate during hemodialysis by using optical data of the spent dialysate. In Proceedings of the 2013 35th Annual International Conference of the IEEE Engineering in Medicine and Biology Society (EMBC), Institute of Electrical and Electronics Engineers (IEEE), Osaka, Japan, 3-7 July 2013; pp. 6707-6710.

24. Masakane, I.; Sakurai, K. Current approaches to middle molecule removal: Room for innovation. Nephrol. Dial. Transplant. 2018, 33, 12-21. [CrossRef]

25. Yamamoto, S. Molecular mechanisms underlying uremic toxin-related systemic disorders in chronic kidney disease: Focused on $\beta 2$-microglobulin-related amyloidosis and indoxyl sulfate-induced atherosclerosis-Oshima Award Address 2016. Clin. Exp. Nephrol. 2019, 23, 151-157. [CrossRef] [PubMed]

26. Clark, W.R.; Dehghani, N.L.; Narsimhan, V.; Ronco, C. Uremic Toxins and their Relation to Dialysis Efficacy. Blood Purif. 2019, 48, 299-314. [CrossRef]

27. Blankestijn, P.J.; Fischer, I.K.; Barth, C.; Cromm, K.; Canaud, B.; Davenport, A.E.; Grobbee, D.; Hegbrant, J.; Roes, K.C.; Rose, M.; et al. Benefits and harms of high-dose haemodiafiltration versus high-flux haemodialysis: The comparison of high-dose haemodiafiltration with high-flux haemodialysis (CONVINCE) trial protocol. BMJ Open 2020, 10, e033228. [CrossRef]

28. Kirsch, A.H.; Lyko, R.; Nilsson, L.-G.; Beck, W.; Amdahl, M.; Lechner, P.; Schneider, A.; Wanner, C.; Rosenkranz, A.R.; Krieter, D.H. Performance of hemodialysis with novel medium cut-off dialyzers. Nephrol. Dial. Transplant. 2016, 32, 165-172. [CrossRef]

29. Lauri, K.; Luman, M.; Holmar, J.; Tomson, R.; Kalle, S.; Arund, J.; Uhlin, F.; Fridolin, I. Can Removal of Middle Molecular Uremic Retention Solutes be Estimated by UV-absorbance Measurements in Spent Dialysate? Springer: Toronto, ON, Canada, 2015; pp. 1297-1300.

30. Uhlin, F.; Holmar, J.; Yngman-Uhlin, P.; Fernström, A.; Fridolin, I. Optical Estimation of Beta 2 Microglobulin during Hemodiafiltration-Does It Work? Blood Purif. 2015, 40, 113-119. [CrossRef] [PubMed]

31. Lauri, K.; Arund, J.; Holmar, J.; Tanner, R.; Kalle, S.; Luman, M.; Fridolin, I. Removal of Urea, $\beta 2-$ Microglobulin, and Indoxyl Sulfate Assessed by Absorbance and Fluorescence in the Spent Dialysate During Hemodialysis. ASAIO J. 2019, 66, 698-705. [CrossRef] [PubMed]

32. Wolley, M.J.; Hutchison, C.A. Large uremic toxins: An unsolved problem in end-stage kidney disease. Nephrol. Dial. Transplant. 2018, 33, iii6-iii11. [CrossRef]

33. Ward, A.R.; Greene, T.W.; Hartmann, B.; Samtleben, W. Resistance to intercompartmental mass transfer limits $\beta 2$-microglobulin removal by post-dilution hemodiafiltration. Kidney Int. 2006, 69, 1431-1437. [CrossRef] [PubMed]

34. Brunati, C.C.M.; Gervasi, F.; Cabibbe, M.; Ravera, F.; Menegotto, A.; Querques, M.; Colussi, G. Single Session and Weekly Beta 2Microglobulin Removal with Different Dialytic Procedures: Comparison between High-Flux Standard Bicarbonate Hemodialysis, Post-Dilution Hemodiafiltration, Short Frequent Hemodialysis with NxStage Technology and Automated Peritoneal Dialysis. Blood Purif. 2019, 48, 86-96. [CrossRef]

35. Krochmal, M.; Schanstra, J.P.; Mischak, H. Urinary peptidomics in kidney disease and drug research. Expert Opin. Drug Discov. 2017, 13, 259-268. [CrossRef] [PubMed]

36. Prasad, S.; Mandal, I.; Singh, S.; Paul, A.; Mandal, B.; Venkatramani, R.; Swaminathan, R. Near UV-Visible electronic absorption originating from charged amino acids in a monomeric protein. Chem. Sci. 2017, 8, 5416-5433. [CrossRef]

37. Rosenheck, K.; Doty, P. The Far Ultraviolet Absorption Spectra of Polypeptide and Protein Solutions and Their Dependence on Conformation. Proc. Natl. Acad. Sci. USA 1961, 47, 1775-1785. [CrossRef]

38. Jerotskaja, J.; Lauri, K.; Tanner, R.; Luman, M.; Fridolin, I. Optical dialysis adequacy sensor: Wavelength dependence of the ultra violet absorbance in the spent dialysate to the removed solutes. In Proceedings of the 2006 International Conference of the IEEE Engineering in Medicine and Biology Society, New York, NY, USA, 30 August-3 September 2006; pp. $2960-2963$. 
39. Fridolin, I.; Lindberg, L.-G. On-line monitoring of solutes in dialysate using wavelength-dependent absorption of ultraviolet radiation. Med. Biol. Eng. Comput. 2003, 41, 263-270. [CrossRef]

40. Fonin, A.V.; Sulatskaya, A.I.; Kuznetsova, I.M.; Turoverov, K.K. Fluorescence of Dyes in Solutions with High Absorbance. Inner Filter Effect Correction. PLoS ONE 2014, 9, e103878. [CrossRef] [PubMed]

41. Wang, T.; Zeng, L.-H.; Li, D.-L. A review on the methods for correcting the fluorescence inner-filter effect of fluorescence spectrum. Appl. Spectrosc. Rev. 2017, 52, 883-908. [CrossRef]

42. Lakowicz, J.R. Fluorophores. In Principles of Fluorescence Spectroscopy, 3rd ed.; Lakowicz, J.R., Ed.; Springer US: Boston, MA, USA, 2006; pp. 63-95.

43. Ulrich, P. Protein Glycation, Diabetes, and Aging. Recent Prog. Horm. Res. 2001, 56, 1-22. [CrossRef] [PubMed]

44. Stirban, A.; Gawlowski, T.; Roden, M. Vascular effects of advanced glycation endproducts: Clinical effects and molecular mechanisms. Mol. Metab. 2014, 3, 94-108. [CrossRef]

45. Gugliucci, A. Formation of Fructose-Mediated Advanced Glycation End Products and Their Roles in Metabolic and Inflammatory Diseases. Adv. Nutr. 2017, 8, 54-62. [CrossRef]

46. Perrone, A.; Giovino, A.; Benny, J.; Martinelli, F. Advanced Glycation End Products (AGEs): Biochemistry, Signaling, Analytical Methods, and Epigenetic Effects. Oxidative Med. Cell. Longev. 2020, 2020, 1-18. [CrossRef] [PubMed]

47. Thornalley, P.J.; Rabbani, N. Highlights and Hotspots of Protein Glycation in End-Stage Renal Disease. Semin. Dial. 2009, 22, 400-404. [CrossRef]

48. Mallipattu, S.K.; Uribarri, J. Advanced glycation end product accumulation. Curr. Opin. Nephrol. Hypertens. 2014, 23, 547-554. [CrossRef]

49. Yamamoto, S.; Kazama, J.J.; Wakamatsu, T.; Takahashi, Y.; Kaneko, Y.; Goto, S.; Narita, I. Removal of uremic toxins by renal replacement therapies: A review of current progress and future perspectives. Ren. Replace. Ther. 2016, 2, 43. [CrossRef]

50. Rabbani, N.; Thornalley, P.J. Advanced glycation end products in the pathogenesis of chronic kidney disease. Kidney Int. 2018, 93, 803-813. [CrossRef]

51. Stinghen, A.E.; Massy, Z.A.; Vlassara, H.; Striker, G.E.; Boullier, A. Uremic Toxicity of Advanced Glycation End Products in CKD. J. Am. Soc. Nephrol. 2015, 27, 354-370. [CrossRef] [PubMed]

52. Roberts, M.A.; Thomas, M.C.; Fernando, D.; Macmillan, N.; Power, D.A.; Ierino, F.L. Low molecular weight advanced glycation end products predict mortality in asymptomatic patients receiving chronic haemodialysis. Nephrol. Dial. Transplant. 2006, 21, 1611-1617. [CrossRef] [PubMed]

53. Miyata, T.; Taneda, S.; Kawai, R.; Ueda, Y.; Horiuchi, S.; Hara, M.; Maeda, K.; Monnier, V.M. Identification of pentosidine as a native structure for advanced glycation end products in beta-2-microglobulin-containing amyloid fibrils in patients with dialysis-related amyloidosis. Proc. Natl. Acad. Sci. USA 1996, 93, 2353-2358. [CrossRef] [PubMed]

54. Meerwaldt, R.; Links, T.; Graaff, R.; Thorpe, S.R.; Baynes, J.W.; Hartog, J.; Gans, R.; Smit, A. Simple Noninvasive Measurement of Skin Autofluorescence. Ann. N. Y. Acad. Sci. 2005, 1043, 290-298. [CrossRef]

55. Kalle, S.; Tanner, R.; Luman, M.; Fridolin, I. Free Pentosidine Assessment Based on Fluorescence Measurements in Spent Dialysate. Blood Purif. 2018, 47, 85-93. [CrossRef]

56. Schmitt, A.; Schmitt, J.; Münch, G.; Gasic-Milencovic, J. Characterization of advanced glycation end products for biochemical studies: Side chain modifications and fluorescence characteristics. Anal. Biochem. 2005, 338, 201-215. [CrossRef] [PubMed]

57. Tessier, F.; Obrenovich, M.; Monnier, V.M. Structure and Mechanism of Formation of Human Lens Fluorophore LM-1. J. Biol. Chem. 1999, 274, 20796-20804. [CrossRef]

58. Miyata, T.; Oda, O.; Inagi, R.; Iida, Y.; Araki, N.; Yamada, N.; Horiuchi, S.; Taniguchi, N.; Maeda, K.; Kinoshita, T. beta 2Microglobulin modified with advanced glycation end products is a major component of hemodialysis-associated amyloidosis. $J$. Clin. Investig. 1993, 92, 1243-1252. [CrossRef]

59. Förster, T. Experimentelle und theoretische Untersuchung des zwischenmolekularen Übergangs von Elektronenanregungsenergie. Z. Nat. A 1949, 4, 321-327. [CrossRef]

60. Förster, T. Delocalized Excitation and Excitation Transfer; Florida State University: Tallahassee, FL, USA, 1965.

61. Donadio, C.; Calia, D.; Ghimenti, S.; Onor, M.; Colombini, E.; Fuoco, R.; Di Francesco, F. The Removal of $\beta 2-$ Microglobulin in Spent Dialysate Cannot Be Monitored by Spectrophotometric Analysis. Blood Purif. 2015, 40, 109-112. [CrossRef]

62. Vivian, J.T.; Callis, P.R. Mechanisms of Tryptophan Fluorescence Shifts in Proteins. Biophys. J. 2001, 80, 2093-2109. [CrossRef]

63. Narang, D.; Sharma, P.K.; Mukhopadhyay, S. Dynamics and dimension of an amyloidogenic disordered state of human $\beta 2-$ microglobulin. Eur. Biophys. J. 2013, 42, 767-776. [CrossRef] [PubMed]

64. Esbensen, K. Multivariate Data Analysis -in Practice. Introduction to Multivariate Data Analysis and Experimental Design, 5th ed.; CAMO Software: Oslo, Norway, 2009.

65. Eloot, S.; Dhondt, A.; Vierendeels, J.; De Wachter, D.; Verdonck, P.; Vanholder, R. Temperature and concentration distribution within the Genius(R) dialysate container. Nephrol. Dial. Transplant. 2007, 22, 2962-2969. [CrossRef] [PubMed]

66. Giavarina, D. Understanding Bland Altman analysis. Biochem. Med. 2015, 25, 141-151. [CrossRef] [PubMed] 